\title{
Malignant fibrous histiocytoma of sternum: an unusual cause of pyrexia of undetermined origin
}

\author{
A. Grieco, S. Caputo, E. Silvestri ${ }^{1}$, P. Caradonna, A. Bertoli and A.V. Greco \\ Istituto di Clinica Medica Generale e Terapia Medica and 'Istituto di Anatomia Patologica, Policlinico \\ Universitario A. Gemelli, Università Cattolica del Sacro Cuore, Largo A. Gemelli 8. 00168-Rome, Italy.
}

\begin{abstract}
Summary: Malignant fibrous histiocytoma of the bone is a very rare tumour mainly affecting long bones, and the most common presenting symptom is local pain. A case of malignant fibrous histiocytoma presenting with pyrexia of undetermined origin and arising in the sternum, a localization not previously described, is reported. The patient died with septic shock after multi-drug chemotherapy including high dose methotrexate treatment with citrovorum factor rescue.
\end{abstract}

\section{Introduction}

Malignant fibrous histiocytoma (MFH) is a malignant tumour consisting of a pleomorphic population of a group of cells sharing a common, less differentiated precursor cell with an expressed potential of differentiating into two major cell populations: foam cells with a histiocyte function, and malignant nucleated cells with a fibrogenetic function disposed in a 'storiform' pattern. ${ }^{1,2}$

Although the tumour arises not uncommonly from soft tissue, it only rarely occurs as a primary bone tumour. ${ }^{3-6}$ Long bones are mainly affected, although MFH has also been described in flat bones such as the calvarium, sacrum, scapulae, patella and mandible. ${ }^{5}$ The commonest clinical sign is local pain. ${ }^{2,5}$

We report the case of a man with a MFH arising from the sternum whose symptom was initially pyrexia of undetermined origin (PUO).

\section{Case report}

A 42 year old man was admitted, complaining of continuous-remittent fever lasting more than 3 months, up to $39.5^{\circ} \mathrm{C}$, resistant to antibiotics and nonsteroidal anti-inflammatory drugs. On admission, his temperature was $39.5^{\circ} \mathrm{C}$. The only abnormal sign was a red macular skin lesion about $2 \mathrm{~cm}$ in diameter over his sternum.

The erythrocyte sedimentation rate was $108 \mathrm{~mm} / \mathrm{h}$ (1st hour), red blood cell count was a $5.26 \times 10^{12} / 1$, white cell count was $18 \times 10^{9} / 1$ (88\% neutrophils), platelet count was $345 \times 10^{9} / 1$. Blood creatinine level

Correspondence: A. Grieco, M.D.

Accepted: 12 May 1989 was normal. Rheumatoid tests were negative, antibodies to double-stranded DNA and antinuclear antibodies were absent. Serum protein electrophoresis was normal. Repeated blood cultures were negative. Barium enema was normal. Lumbar puncture yielded clear cerebrospinal fluid, normal on cytology and culture. Bone marrow culture was negative.

The patient began to complain of pain in the sternal region with paresthesiae corresponding to the reds macular lesion. The fever pattern was unchanged.

Radiological examination revealed an ill-defined area in the lower sternum. A scintigraphic scan showed a 'cold lesion' and tomography confirmed the radiological finding. Surgical inspection of the sternal region showed the presence of a neoplastic, hardelastic, lobulated, bleeding mass in the area, with no cleavage wall from surrounding tissues. The histological appearance of the tumour was characterized by giant histiocytes, fibroblasts and spindle cells. Areas of tissue necrosis and vascular slits lined by anaplastic cells were frequently observed (Figure 1). The 'storiform' pattern of growth was mixed with and even obscured by an intense inflammatory infiltrate rich in granulocytes and plasma cells (Figure 2). The immunohistochemical study showed positive reaction for lysozyme in numerous cells. The diagnosis of 'malignant fibrous histiocytoma' was given.

The neoplasia was judged to be inoperable and so the patient started on antiblastic chemotherapy treatment with the combination of adriamycin, DTIC, vincristine and cyclophosphamide (CYVADIC). ${ }^{7}$ Fever and pain disappeared promptly, with the granulation of the surgical wound. Six months later, after five chemotherapy cycles, fever reappeared, and the sternal wound was occupied by a neoplastic mass, with no evidence of metastases at restaging. Then the

(C) The Fellowship of Postgraduate Medicine, 1989 


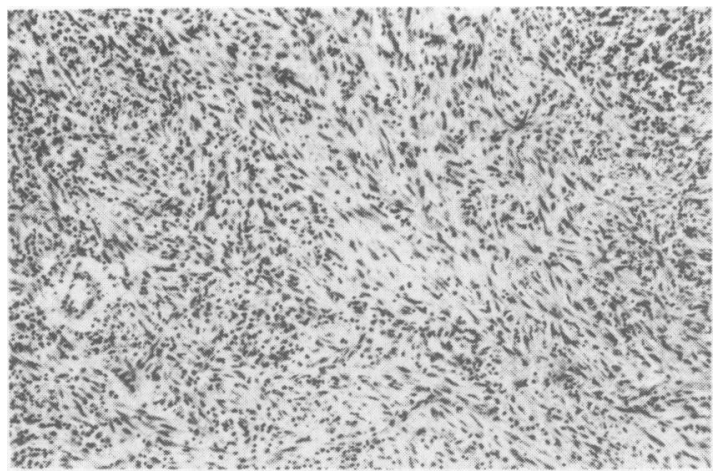

Figure 1 The histological appearance was characterized by 'storiform pattern' of growth, giant cells and an intense inflammatory reaction rich in granulocytes and plasma cells (H\& E X 1.5).

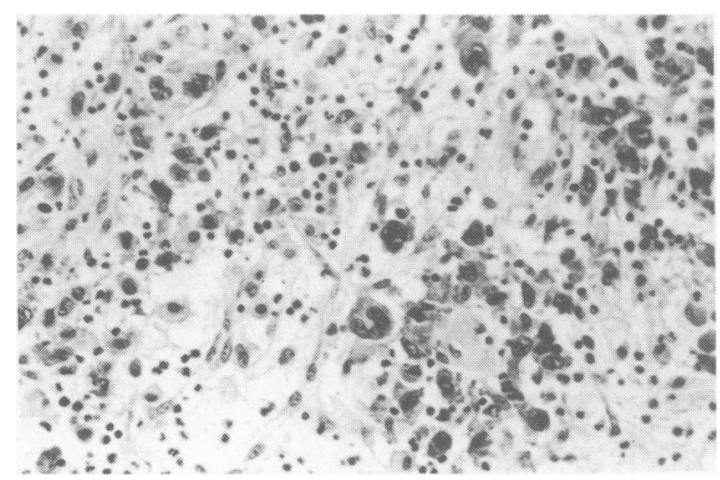

Figure 2 Some giant cells mixed with an intense inflammatory reaction rich in granulocytes and plasma cells are evident in a fibrous stroma (H\& E $\times 24)$.

patient underwent chemotherapy with high dose methotrexate with citrovorum factor rescue supplemented with adriamycin and a combination of bleomycin, cyclophosphamide and dactinomycin, ${ }^{8}$ but after the second course of methotrexate the patient died due to septic shock and marrow aplasia. At autopsy the sternal region showed no tumour tissue. No signs of metastases or other signs of illness were documented.

\section{References}

1. Feldman, F. \& Norman, D. Intra- and extraosseous malignant histiocytoma (Malignant fibrous xanthoma). Radiology 1972, 104: 497-508.

2. Spanier, S.S., Enneking, W.F. \& Enriquez, P. Primary malignant fibrous histiocytoma of bone. Cancer 1975, 36: 2084-2098.

\section{Discussion}

In this case of MFH two interesting aspects are to be stressed: the tumour localization and the clinical onset. MFH as bone tumour was not fully accepted until 1977 when Dahlin ${ }^{3}$ and Spanier ${ }^{4}$ recognized some large series and preparations of osseous tumours previously labelled as osteosarcomas and/or fibrosarcomas, singling out and segregating 15 and 35 cases respectively of lesions that satisfied the characteristics which define the diagnosis of malignant fibrohistiocytoma; $;, 10$ the presence of three cell types identified as spindle fibroblastic-fibrocytic cells, plump cells with histiocytic morphology and giant cells with both benign and malignant appearance; fibrogenic areas with 'storiform' or 'cartwheel' pattern with the fascicles radiating irregularly from focal zones; absence of osteoid.

Up to now, about 300 cases of MFH of the bone have been reported, including both new cases and the reclassified ones. The most important series is that of Capanna ${ }^{5}$ with 90 cases. There are others of 10 cases, ${ }^{11}$ and 8 cases, ${ }^{12}$ and 18 cases. ${ }^{13}$ By far the most frequent site of MFH is a long bone and in particular the femur in about $50 \%$ of cases. A site affected relatively often is the maxilla. ${ }^{14,15}$ Localization at the ensiform process of the sternum has not been reported previously.

MFH seems to be associated with another osseous lesion such as bone infarct, Paget's disease or the site of previous irradiation. Such observations have led some authors to speculate that MFH is the malignant evolution of a bone reparative process because in most chronic reparative processes, continuous remodelling is accompanied by considerable histiocytic activity. ${ }^{4,16,17}$ In the present case no osseous lesion was documented at tumour site and no previous local trauma was reported.

In this case a further peculiar characteristic appears to be the presentation of the illness with pyrexia of undetermined origin. Only the subsequent appearance of pain directed our attention to the site of the disease. In Capanna's series no case presented with fever; the commonest symptom at onset was pain and swelling (with a range $0.7-36$ months before diagnosis). ${ }^{5}$ Even in the Yuen and Ros series the symptoms at onset were characterized by pain appearing with a median time of 8 months (range $1-36$ months) before diagnosis. ${ }^{11,12}$ MFH has to be taken into account in the differential diagnosis of PUO.

3. Dahlin, D.C., Unni, K.K. \& Matsuno, T. Malignant (fibrous) histiocytoma of bone: fact or fancy? Cancer 1977, 39: 1508-1516.

4. Spanier, S.S. Malignant fibrous histiocytoma of bone. Orthop Clin North Am 1977, 8: 947-961. 
5. Capanna, R., Bertoni, F., Bacchini, P., Bacci, G., Guerra, A. \& Campanacci, M. Malignant fibrous histiocytoma of bone. The experience at the Rizzoli Institute: report of 90 cases. Cancer 1984, 54: 177-187.

6. Den Heeten, G.J., Schraffordt Koops, H., Kamps, W.A., Oosterhuis, J.W., Sleijfer, D. Th. \& Oldhoff, J. Treatment of malignant fibrous histiocytoma of bone. Cancer 1985, 56: 37-40.

7. Leite, C., Goodwin, J., Sinkovics, J., Baker, L.H. \& Benjamin, R. Chemotherapy of malignant fibrous histiocytoma. Cancer 1977, 40: 2010-2024.

8. Rosen, G., Marcove, R., Caparros, B., Nirenberg, A., Kosloff, C. \& Huvos, A.G. Primary osteogenic sarcoma: the rationale for preoperative chemotherapy and delayed surgery. Cancer 1979, 43: 2163-2177.

9. Soule, E.H. \& Enriquez, P. Atypical fibrous histiocytoma, malignant fibrous histiocytoma, malignant histiocytoma and epithelioid sarcoma: a comparative study of 65 tumors. Cancer 1972, 30: 128-143.

10. Kempson, R.L. \& Kyriakos, M. Fibroxanthosarcoma of the soft tissues: a type of malignant fibrous histiocytoma. Cancer 1972, 29: 961-976.

11. Ros, P.R., Viamonte, M. \& Rywlin, A.M. Malignant fibrous histiocytoma: mesenchymal tumor of ubiquitous origin. AJR 1984, 142: 753-759.
12. Yuen, W.W.H. \& Saw, D. Malignant fibrous histiocytoma of bone. J Bone Joint Surg (Am) 1985, 67: $482-486$.

13. Huvos, A.G. Primary malignant fibrous histiocytoma of bone. Clinicopathologic study of 18 patients. NY State J Med 1976, 76: 552-559.

14. Block, M.S., Cade, J.E. \& Rodriguez, F.H. Malignant fibrous histiocytoma in the maxilla. $J$ Oral Maxillofac Surg 1986, 44: 404-412.

15. Unger, P.D., Kaneko, M. \& Thung, S.N. Malignant fibrous histiocytoma of the maxillary sinus. Mount Sinai $J$ Med 1985, 52: 569-574.

16. Mirra, J.M., Gold, R.H. \& Marafioti, R. Malignant (fibrous) histiocytoma and osteosarcoma in association with bone infarcts. Report of four cases: two in caisson workers. J Bone Joint Surg (Am) 1974, 56: 932-940.

17. Dunham, W.K. \& Wilborn, W.H. Malignant fibrous histiocytoma of bone. J Bone Joint Surg (Am) 1979, 61: 939-942.

18. Larson, E.B., Featherstone, H.J. \& Petersdorf, R.G. Fever of undetermined origin: diagnosis and follow-up of 105 cases, 1970-1980. Medicine 1982, 61: 269-292. 